\title{
Thermoelastic Characteristics in Thermal Barrier Coatings with a Graded Layer between the Top and Bond Coats
}

\author{
Seokchan Kim, ${ }^{1}$ Jaegwi Go, ${ }^{1}$ Yeon-Gil Jung, ${ }^{2}$ and Je-Hyun Lee ${ }^{2}$ \\ ${ }^{1}$ Department of Mathematics, Changwon National University, 9 Sarim-dong, Changwon 641-773, Republic of Korea \\ ${ }^{2}$ School of Nano and Advanced Materials Engineering, Changwon National University, 9 Sarim-dong, \\ Changwon 641-773, Republic of Korea \\ Correspondence should be addressed to Jaegwi Go; jggo@changwon.ac.kr
}

Received 6 December 2012; Accepted 20 February 2013

Academic Editor: Abdelouahed Tounsi

Copyright (C) 2013 Seokchan Kim et al. This is an open access article distributed under the Creative Commons Attribution License, which permits unrestricted use, distribution, and reproduction in any medium, provided the original work is properly cited.

\begin{abstract}
A graded layer was introduced at the interface between the top and bond coats to reduce the risk of failure in a thermal barrier coating (TBC) system, and the thermoelastic behavior was investigated through mathematical approaches. Two types of TBC model with and without the graded layer, subject to a symmetric temperature distribution in the longitudinal direction, were taken into consideration to evaluate thermoelastic behaviors such as temperature distribution, displacement, and thermal stress. Thermoelastic theory was applied to derive two governing partial differential equations, and a finite volume method was developed to obtain approximations because of the complexity. The TBC with the graded layer shows improved durability in thermoelastic characteristics through mathematical approaches, in agreement with the experimental results. The results will be useful in discovering technologies for enhancing the thermomechanical properties of TBCs.
\end{abstract}

\section{Introduction}

The deposition process for thermal barrier coatings (TBCs) exerts a critical influence on the determination of the thermomechanical properties, such as elastic modulus, thermal conductivity, and coefficient of thermal expansion. Moreover, failure phenomena usually occur at the interface between the top and bond coats because of the mismatch of mechanical and thermal properties as the TBC system cools from a high operating temperature to ambient temperature. To improve the thermal durability of TBCs for protecting hot components such as combustors and turbine parts, functionally graded materials (FGMs) and composite materials (CMs) are widely employed [1-9]. FGMs consist of two or more distinct material phases whose volume fractions continuously vary with space variables, thus yielding continuously varying mechanical and thermal properties in the FGM system. CMs are products composed of two or more distinct constituent materials involving different physical or chemical properties such that their constituents remain still distinguishable at the macroscopic or microscopic scale within the structure. The original purpose of these materials is, simultaneously, to resist high temperature and ensure low thermal conductivity through TBC techniques.

CMs make use of improved characteristics such as strength, fatigue life, stiffness, temperature-dependent behavior, thermal insulation, thermal conductivity, and weight. For example, TBCs are applied in building aircraft to obtain light and strong materials in surfacing while insulating against hazardous physical factors such as heat and lightning. In aircraft, aerospace, automotive, and shipping applications, fiberreinforced and resin-matrix CMs contribute to the improvement through their higher strength and stiffness benefits [10-12]. However, owing to different macroscopic or microscopic scales within the structure, CMs are exposed to the risk of delamination during service. On the other hand, FGMs represent improved bonding strength, toughness, wear and corrosion resistance, and reduced residual and thermal stresses because of the graded material properties. These outstanding advantages of FGMs over conventional composites and monolithic materials have led to extensive study for potential applications as structural elements, such as FGM beams $[13,14]$, plates $[15,16]$, shells [17], and cylinders [18, 19], and have provoked the interest of researchers toward 
the development of potential new structural and functional applications. Therefore, FGMs and CMs are being explored to determine their characteristics from various points of view.

The microstructural characterizations of TBCs are greatly influenced by the size, shape, and density of the feedstock powder [20-23]. In addition, the deposition process parameter is an essential element in determining its microstructure. Cernuschi et al. [24] and Jung et al. [25] analyzed the microstructure features of TBCs manufactured using the air plasma spray process, and the effects of thermal annealing on the microstructure of TBCs deposited by electron beam physical vapor deposition have been investigated by Kulkarni et al. [26] and Schulz and Schmücker [27]. Moreover, the study of microstructural behavior has been extended to functionally graded (FG) TBC materials. The microstructure and phase stability of FG TBCs based on $\mathrm{LaMgAl}_{11} \mathrm{O}_{19}$ (LaMa)/YSZ have been investigated by $\mathrm{Chen}$ et al. [28], and the results indicated that all of the LaMa and LaMa-containing intermediate composite coatings suffer irreversible phase transformations induced by the recrystallization of amorphous LaMa coating. Schulz et al. [29] tried to optimize the thermal, wear, and corrosion properties of FGMs and found that TBCs deposited onto Cu substrates by pulsed laser deposition showed improved spallation behavior by a graded lamella microstructure with improved interface fracture toughness. Shaw [30] studied the thermal residual stresses in multilayered and compositionally graded plates and coatings.

In the present paper, the thermoelastic characteristics of circular disk TBC specimens with and without an FG layer between the top and bond coats are analyzed through mathematical approaches. Two partial differential equations are derived based on thermoelastic theory, and the thermoelastic characteristics, such as temperature distribution profiles, displacement, and stresses, are determined through mathematical approaches. Because of the complexity of the governing equations, a finite volume approach is adopted to analyze the thermoelastic characteristics.

\section{Mathematical Modeling}

2.1. Thermoelastic Formulation. According to the assumption that the temperature profiles pressure the circular disk to the longitudinal direction only, all quantities are independent of circumferential $\theta$-direction. Equilibrium equations in polar coordinates thus are

$$
\begin{gathered}
\frac{\partial \sigma_{r}}{\partial r}+\frac{\partial \tau_{r z}}{\partial z}+\frac{\sigma_{r}-\sigma_{\theta}}{r}=0 \\
\frac{\partial \tau_{r z}}{\partial r}+\frac{\partial \sigma_{z}}{\partial z}+\frac{\tau_{r z}}{r}=0
\end{gathered}
$$

Let $u$ be the displacement to the radial direction, and let $w$ be the displacement to the longitudinal direction. The straindisplacement relations are as follows:

$$
\begin{gathered}
\varepsilon_{r}=\frac{\partial u}{\partial r}, \quad \varepsilon_{\theta}=\frac{u}{r}, \quad \varepsilon_{z}=\frac{\partial w}{\partial z}, \\
\gamma_{r \theta}=0, \quad \gamma_{z \theta}=0, \quad \gamma_{r z}=\frac{\partial u}{\partial z}+\frac{\partial w}{\partial r} .
\end{gathered}
$$

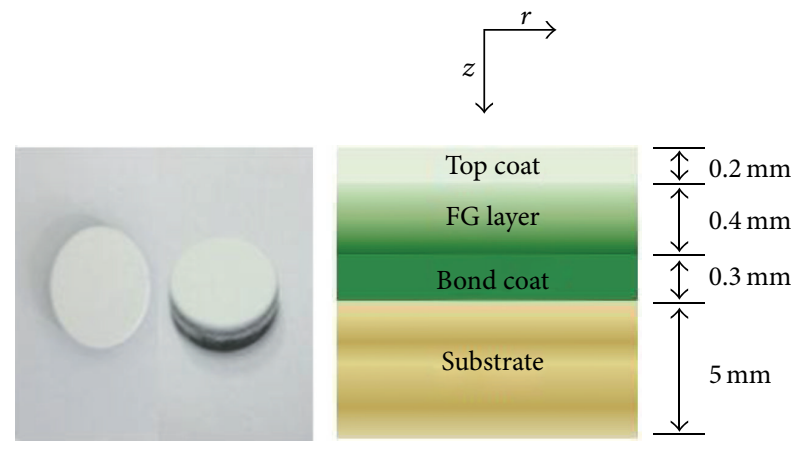

FIGURE 1: Schematic diagram of a circular disk model for thermoelastic characteristics of TBCs.

In addition, the strain-stress relations due to the action of thermal loading can be expressed as

$$
\begin{gathered}
\varepsilon_{r}=\frac{1}{E}\left[\sigma_{r}-\nu\left(\sigma_{\theta}+\sigma_{z}\right)\right]+\alpha T, \\
\varepsilon_{\theta}=\frac{1}{E}\left[\sigma_{\theta}-\nu\left(\sigma_{r}+\sigma_{z}\right)\right]+\alpha T, \\
\varepsilon_{z}=\frac{1}{E}\left[\sigma_{z}-\nu\left(\sigma_{r}+\sigma_{\theta}\right)\right]+\alpha T, \\
\tau_{r \theta}=G \gamma_{r \theta}=0, \quad \tau_{\theta z}=G \gamma_{\theta z}=0, \\
\tau_{r z}=G \gamma_{r z},
\end{gathered}
$$

where $G=2 E(1+\nu)$.

The combination of (1)-(3) leads to the following governing equations:

$$
\begin{gathered}
-K(1-v) r \frac{\partial}{\partial r}\left(r \frac{\partial u}{\partial r}\right)+G r^{2} \frac{\partial}{\partial z}\left(\frac{\partial u}{\partial z}\right)+K(1-v) u=0 \\
-K(1-v) r \frac{\partial}{\partial z}\left(\frac{\partial w}{\partial z}\right)+(G-K \nu) r \frac{\partial}{\partial r}\left(\frac{\partial u}{\partial z}\right) \\
+(G-K \nu) \frac{\partial u}{\partial z}+K \alpha(1+\nu) r \frac{\partial T}{\partial z}=0
\end{gathered}
$$

where $K=E /(1+v)(2 v-1)$.

2.2. Temperature Distribution Formulation. Since the circular disk is subject to a uniform temperature loading in the longitudinal $z$-direction only (see Figure 1), the differential equation for the temperature distribution profile is

$$
\frac{\partial^{2} T}{\partial z^{2}}=0
$$

The general solution of (5) is

$$
T(z)=c_{i 1} z+c_{i 2},
$$


where $c_{i 1}$ and $c_{i 2}$ are integration constants for the $i$ th layer temperature distribution. The integration constants will be determined based on the following boundary conditions:

$$
\begin{gathered}
T\left(z_{0}\right)=T_{\text {in }}, \quad T\left(z_{1}\right)=T_{1}, \quad T\left(z_{2}\right)=T_{2}, \\
T\left(z_{3}\right)=T_{3}, \quad T\left(z_{b}\right)=T_{\text {out }},
\end{gathered}
$$

but only two boundary values $T_{\text {in }}$ and $T_{\text {out }}$ are known, and so heat flux at each layer point is considered. The heat flux at $i$ th layer point is expressed as

$$
q_{i}=\frac{k_{i}}{L_{i}}\left(T_{i-1}-T_{i}\right), \quad q_{i}=q_{i+1},
$$

where $q_{i}$ is the heat flux into $i$ th layer, $k_{i}$ is the conductivity, and $L_{i}$ is the length of $i$ th layer. At each $i$ th layer point, the integral constants for the temperature distribution profile are determined uniquely by solving the following linear system:

$$
\begin{gathered}
c_{i 1} z_{i-1}+c_{i 2}=T_{i-1}, \\
c_{i 1} z_{i}+c_{i 2}-T_{i}=0, \\
q_{i}=\frac{k_{i}}{L_{i}}\left(T_{i-1}-T_{i}\right), \quad q_{i}=q_{i+1}, \\
q_{n-1}=\frac{k_{n-1}}{L_{n-1}}\left(T_{n-2}-T_{n-1}\right), \quad q_{n-1}=q_{n}, \\
q_{n}-\frac{k_{n}}{L_{n}} T_{n-1}=-\frac{k_{n}}{L_{n}} T_{\text {out }}, \quad i=1,2, \ldots, n-1 .
\end{gathered}
$$

The $T_{i-1}$ is a known value solved by $(i-1)$ th layer linear system and $T_{\text {out }}$ is a given initial value, and thus the number of $2(n-i)+3$ equations will determine $2(n-i)+3$ 's unknown coefficients. Here, $n$ is the number of layers. The temperature distribution profiles obtained through this process will be applied to (4a) and (4b) for the thermoelastic characteristics.

2.3. FG Layer Formulation. The elastic modulus E, Poisson's ratio $\nu$, thermal expansion coefficient $\alpha$, and thermal conductivity $k$ are assumed to vary exponentially with the variable $z$; that is,

$$
\begin{aligned}
& E=E_{0} e^{\delta_{1} z}, \\
& \nu=\nu_{0} e^{\delta_{2} z}, \\
& \alpha=\alpha_{0} e^{\delta_{3} z}, \\
& k=k_{0} e^{\delta_{4} z} .
\end{aligned}
$$

The inner area of the circular disk $\left(z=z_{1}\right)$ consists of $100 \%$ of the top coat material, whereas the outer area of the disk $(z=$ $z_{2}$ ) has $100 \%$ of the bond coat material; that is, the properties in (10a), (10b), (10c), and (10d) have values equal to those of

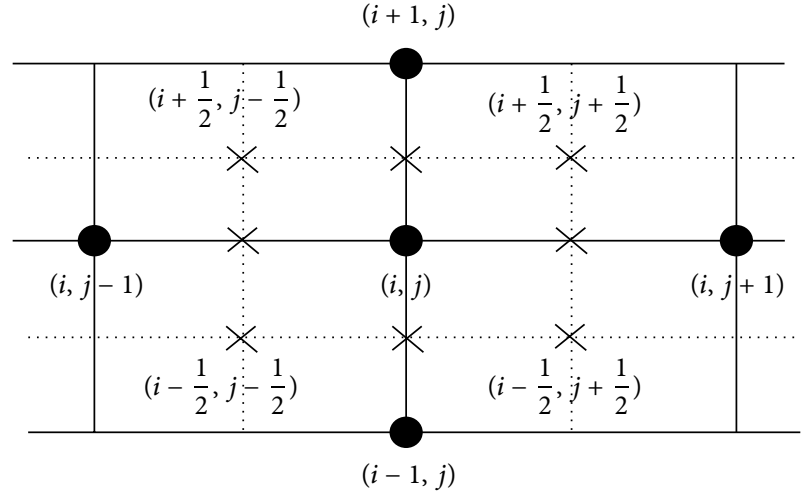

Figure 2: Finite volume mesh for a two-dimensional domain.

the materials in the top and bond coats, respectively, at the inner and outer areas of the disk. Thus, the constants in (4a) and $(4 \mathrm{~b})$ can be determined as

$$
\begin{gathered}
E_{0}=E_{T} e^{-\delta_{1} z_{1},} \\
v_{0}=\nu_{T} e^{-\delta_{2} z_{1}}, \\
\alpha_{0}=\alpha_{T} e^{-\delta_{3} z_{1}}, \\
k_{0}=k_{T} e^{-\delta_{4} z_{1}}, \\
\delta_{1}=\frac{1}{z_{1}-z_{2}} \ln \left(\frac{E_{T}}{E_{B}}\right), \\
\delta_{2}=\frac{1}{z_{1}-z_{2}} \ln \left(\frac{\nu_{T}}{\nu_{B}}\right), \\
\delta_{3}=\frac{1}{z_{1}-z_{2}} \ln \left(\frac{\alpha_{T}}{\alpha_{B}}\right), \\
\delta_{4}=\frac{1}{z_{1}-z_{2}} \ln \left(\frac{k_{T}}{k_{B}}\right) .
\end{gathered}
$$

The subscripts $T$ and $B$ on a variable represent the properties of the constituent materials in the top and bond coats, respectively. The mechanical and thermal properties obtained through this process will be used to analyze the thermoelastic characteristics of graded layer between the top coat and bond coat.

2.4. Discretization of the Governing Equation Based on a Finite Volume Method. The governing equations for the microstructural characterization of TBCs are too complicated to be solved analytically, and a finite volume method is adopted for numerical approximations. The model is divided up into control volumes and integrates the field equations over each control volume (see Figure 2). In formulating a numerical approximation for the present problem, the finite 
surface mesh is denoted by $(i, j)$, and the discretizations for the governing equations are developed based on the following relations at the adjacent locations:

$$
\begin{gathered}
\left(\frac{\partial u}{\partial r}\right)_{i, j+1 / 2}=\frac{u_{i, j+1}-u_{i, j}}{\Delta r}, \\
\left(\frac{\partial u}{\partial r}\right)_{i, j-1 / 2}=\frac{u_{i, j}-u_{i, j-1}}{\Delta r}, \\
\left(\frac{\partial u}{\partial r}\right)_{i, j-1}=\frac{u_{i, j+1}-u_{i, j-1}}{2 \Delta r}, \\
\left(\frac{\partial w}{\partial z}\right)_{i, j}=\frac{1}{2 \Delta z}\left(3 w_{i, j}-4 w_{i-1, j}+w_{i-2, j}\right), \\
w_{m+1 / 2, j+1}=w_{m, j+1} \\
+\frac{1}{4}\left(3 w_{m, j+1}-4 w_{m-1, j+1}+w_{m-2, j+1}\right), \\
w_{m-1 / 2, j+1}=w_{m-1, j+1}+\frac{1}{4}\left(w_{m, j+1}-w_{m-2, j+1}\right), \\
\phi_{i+1 / 2, j+1 / 2}=\frac{1}{2}\left(\phi_{i+1 / 2, j+1}+\phi_{i+1 / 2, j}\right) .
\end{gathered}
$$

In the previous equations a subscript $1 / 2$ implies the value of the displacement at the boundary of the control surface. According to the above relations at the adjacent locations, (4a) is discretized as follows:

$$
\begin{gathered}
u_{i+1, j}\left[G_{i} r_{j}^{2} \frac{\Delta r}{\Delta z}\right]+u_{i, j+1}\left[K_{i}\left(1-v_{i}\right) r_{j} r_{j+1 / 2} \frac{\Delta z}{\Delta r}\right] \\
+u_{i, j-1}\left[K_{i}\left(1-v_{i}\right) r_{j} r_{j-1 / 2} \frac{\Delta z}{\Delta r}\right]+u_{i-1, j}\left[G_{i} r_{j}^{2} \frac{\Delta r}{\Delta z}\right] \\
+u_{i, j}\left[K_{i}\left(1-v_{i}\right)\right. \\
\times\left(\Delta r \Delta z-r_{j}\left(r_{j+1 / 2}+r_{j-1 / 2}\right) \frac{\Delta z}{\Delta r}\right) \\
\left.-2 G_{i} r_{j}^{2} \frac{\Delta r}{\Delta z}\right]=0 .
\end{gathered}
$$

Similar process is adjusted to (4b) and arrives at

$$
\begin{aligned}
u_{i, j+1} & {\left[\frac{1}{8}\left(G_{i}-K_{i} v_{i}\right)\left(5 r_{j}+4 \Delta r\right)\right] } \\
- & -u_{i, j}\left[\frac{1}{8}\left(G_{i}-K_{i} v_{i}\right)\left(10 r_{j}+8 \Delta r\right)\right] \\
+ & +u_{i, j-1}\left[\frac{1}{8}\left(G_{i}-K_{i} v_{i}\right)\left(5 r_{j}+4 \Delta r\right)\right] \\
& -u_{i-1, j+1}\left[\left(G_{i}-K_{i} v_{i}\right) r_{j}\right] \\
& +u_{i-1, j}\left[2\left(G_{i}-K_{i} v_{i}\right) r_{j}\right] \\
& -u_{i-1, j-1}\left[\left(G_{i}-K_{i} v_{i}\right) r_{j}\right]
\end{aligned}
$$

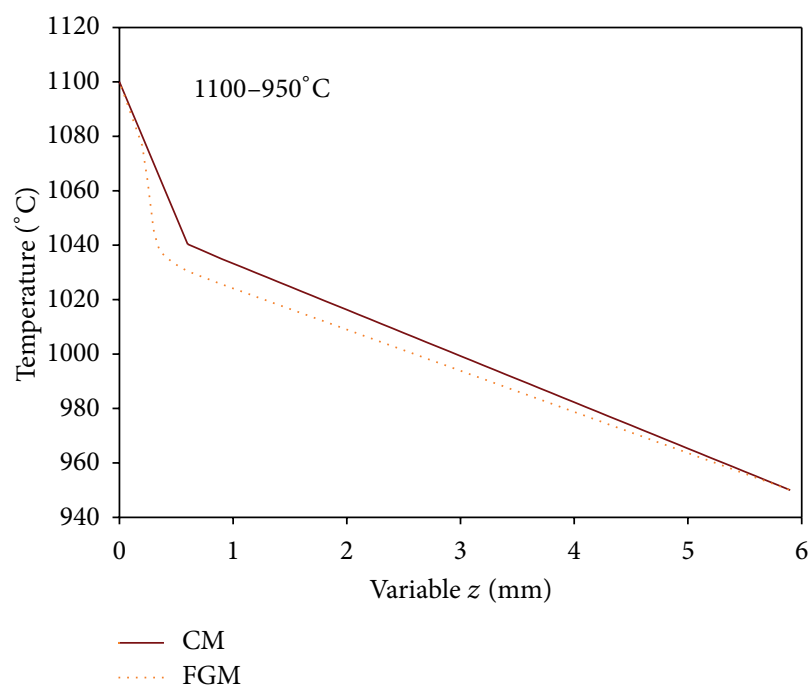

FIgURE 3: Temperature distribution profiles under the symmetric temperature distribution of $1100-950^{\circ} \mathrm{C}$.

$$
\begin{aligned}
& +u_{i-2, j+1}\left[\frac{3}{8}\left(G_{i}-K_{i} v_{i}\right) r_{j}\right] \\
& -u_{i-2, j}\left[\frac{1}{8}\left(G_{i}-K_{i} v_{i}\right) r_{j}\right] \\
& +u_{i-2, j-1}\left[\frac{3}{8}\left(G_{i}-K_{i} v_{i}\right) r_{j}\right] \\
& -w_{i+1, j}\left[K_{i}\left(1-v_{i}\right) r_{j} \frac{\Delta r}{\Delta z}\right] \\
& +w_{i, j}\left[2 K_{i}\left(1-v_{i}\right) r_{j} \frac{\Delta r}{\Delta z}\right] \\
& -w_{i-1, j}\left[K_{i}\left(1-v_{i}\right) r_{j} \frac{\Delta r}{\Delta z}\right] \\
& =K_{i} \alpha_{i}\left(1+v_{i}\right) r_{j} \Delta r\left[T_{i-1 / 2}-T_{1+1 / 2}\right] .
\end{aligned}
$$

The finite volume model is developed based on the following boundary conditions:

$$
\begin{gathered}
u(0, z)=0, \quad u(R, z)=0, \quad \sigma_{r}(R, z)=0, \\
\sigma_{z}(r, 0)=0, \quad \sigma_{z}\left(r, z_{b}\right)=0 .
\end{gathered}
$$

\section{Results and Discussion}

The temperature distribution profiles and thermoelastic characteristics were investigated based on the mechanical and thermal properties shown in Table 1 using the processes in Sections 2.2 and 2.3. The mechanical and thermal properties of the FG layer are obtained based on (11a), (11b), (11c), and (11d). The temperature distribution profiles of the TBCs with and without the FG layer are shown in Figure 3. At the top coat of the TBC without the FG layer (hereafter CM), the decrease in temperature is linear, while the TBC with the FG layer (hereafter FGM) exhibits an exponential decrease. 
TABLE 1: Mechanical and thermal properties used in this study for analyzing thermoelastic characteristics.

\begin{tabular}{|c|c|c|c|c|}
\hline Material/property & Elastic module (GPa) & Poisson's ratio & $\begin{array}{l}\text { Thermal expansion coefficient } \\
\left(10^{-6} /{ }^{\circ} \mathrm{C}\right)\end{array}$ & $\begin{array}{l}\text { Thermal conductivity } \\
\left(\mathrm{W} / \mathrm{m}^{\circ} \mathrm{C}\right)\end{array}$ \\
\hline $\begin{array}{l}\text { Top coat* } \\
\left(8 \text { wt } \% \mathrm{Y}_{2} \mathrm{O}_{3} \text { doped } \mathrm{ZrO}_{2}\right)\end{array}$ & 100 & 0.2 & $9.5\left(20-1300^{\circ} \mathrm{C}\right)$ & 2.0 \\
\hline $\begin{array}{l}\text { Bond coat } \\
\text { (AMDRY 995C) }\end{array}$ & 200 & 0.3 & 14 & 11 \\
\hline $\begin{array}{l}\text { Substrate } \\
\text { (NIMONIC 263) }\end{array}$ & 221 & 0.3 & $11.1\left(20-100^{\circ} \mathrm{C}\right)$ & 11.7 \\
\hline
\end{tabular}

"Properties of the top coat prepared using an air plasma spray with METCO 204 NS-G powder.

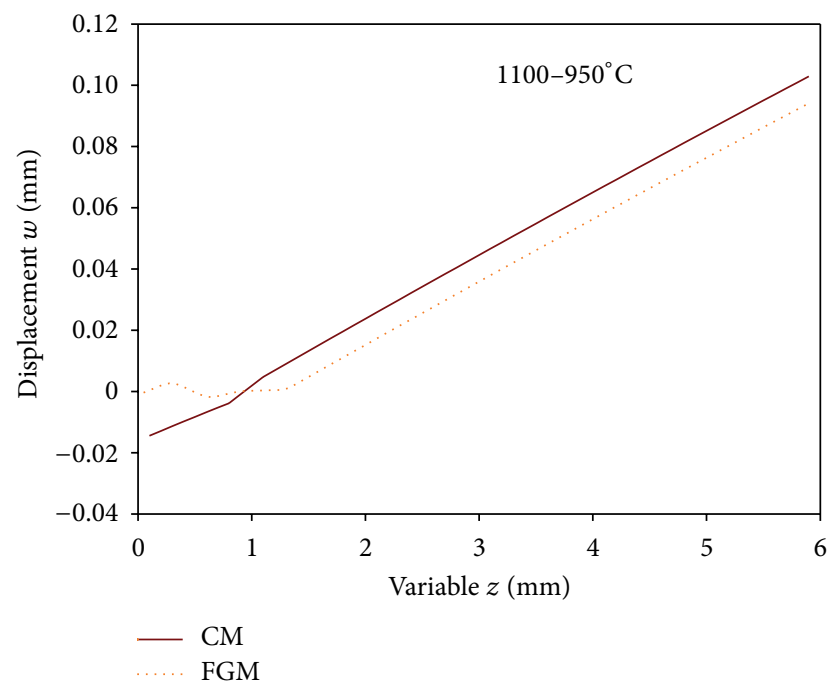

FIGURE 4: Displacement in the longitudinal direction of TBCs under the symmetric temperature distribution of $1100-950^{\circ} \mathrm{C}$.

Over the entire domain, the circle with the FG layer is under a loading from a lower temperature, which implies an improved durability for the FGM. The rate of temperature decrease becomes slower as the metal concentration increases along the longitudinal direction and demonstrates that the mathematical approach is reliable and reasonable.

The longitudinal and radial displacement profiles are presented in Figures 4 and 5, respectively. Unlike the displacement profile of the CM at the top and bond coats, the longitudinal displacement of the FGM fluctuates at the top coat, the FG layer, and the bond coat (see Figure 4). At the substrate, the two models exhibit similar behavior, although a lower displacement develops along the $z$-direction in the FGM. The radial displacement profiles of each layer in the FGM are displayed in Figure 5(a). At the top coat, a larger fluctuation appears near the center, while the magnitude of the radial displacement at the FG layer is almost constant for the interval $0<r<7$, which implies that the durability is increased through the FG layer. A small radial displacement develops at the bond coat because of the relaxation of delamination. The radial behaviors at the bond coat in both the CM and the FGM are compared in Figure 5(b). The magnitude of the radial displacement of the FGM is almost negligible, whereas the bond coat of the CM undulates with a large magnitude in comparison with the FGM.

Figure 6 represents the longitudinal and circumferential stresses. The tensile longitudinal stress appearing at the interface between the bond coat and the substrate of the CM converts into a compressive stress in the FGM, and the FGM experiences larger compressive longitudinal stress at the top coat, the FG layer, and the bond coat (see Figure 6(a)), indicating that the FGM will improve the thermal stability of the TBC system during service. A tensile longitudinal stress develops at the substrate in the FGM. In the circumferential stress, the magnitude is larger at the top coat, the FG layer, and the bond coat in the FGM; on the other hand, a smaller magnitude appeared at the substrate (see Figure 6(b)). Both models are influenced by the compressive circumferential stress over the entire domain.

The radial stress profiles are displayed in Figure 7. At the top coat, the largest undulation occurs near the center and the magnitude decreases as the radius $r$ increases (see Figure 7(a)). A fluctuation with the smallest magnitude develops at the bond coat because of the alleviation of stress at the FG layer. A comparison of the radial stress at the bond coat between the CM and the FGM is shown in Figure 7(b). For the interval $3<r<6$, a large fluctuation is produced in the CM, while the influence of the radial stress is negligible in the FGM, showing the superiority of the FGM.

Overall, as compared with the models, the FG layer in TBCs provides buffer zone interactions between the top coat and the bond coat and absorbs critical shocks. This phenomenon is shown through the thermoelastic behavior at the bond coat of the FGM: (i) the magnitude of the radial displacement is trivial in comparison with that of the CM, (ii) the tensile longitudinal stress at the interface between the bond coat and the substrate in the CM converts into a compressive stress, and (iii) a negligible fluctuation is developed along the radius in comparison with that of the $\mathrm{CM}$. The results demonstrate that the thermal durability of the TBC can be improved by introducing an FG layer between the top coat and the bond coat, and the mathematical analysis presented is a reasonable approach. The results and analysis performed here contribute further understanding to the behavior of TBCs. 


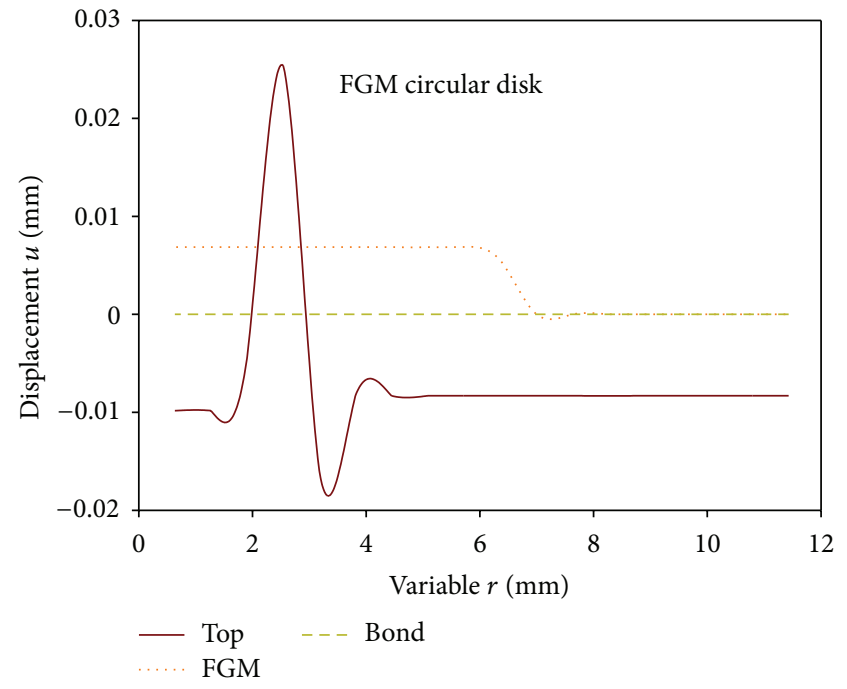

(a)

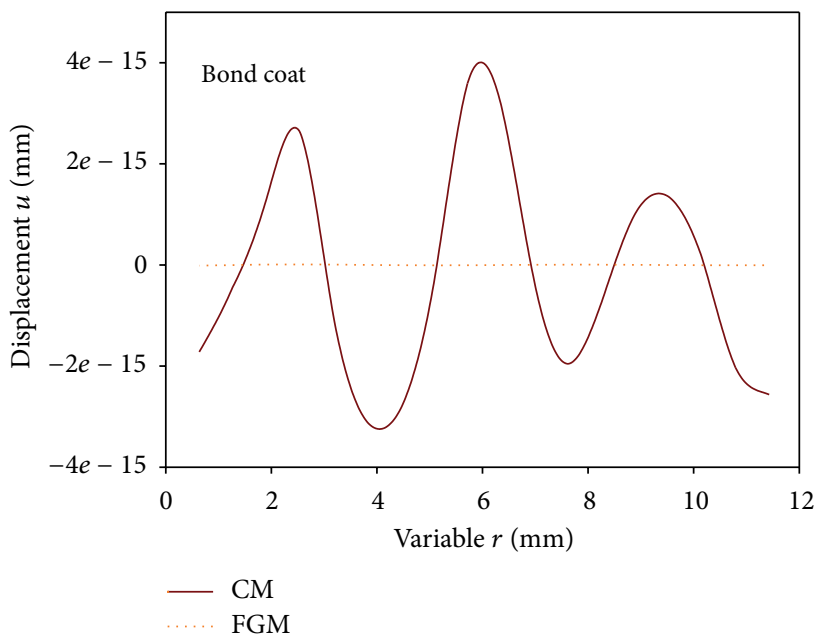

(b)

FIGURE 5: Displacement in the radial direction of TBCs under the symmetric temperature distribution of $1100-950^{\circ} \mathrm{C}$ : (a) TBC with FG layer and (b) comparison at the bond coat.

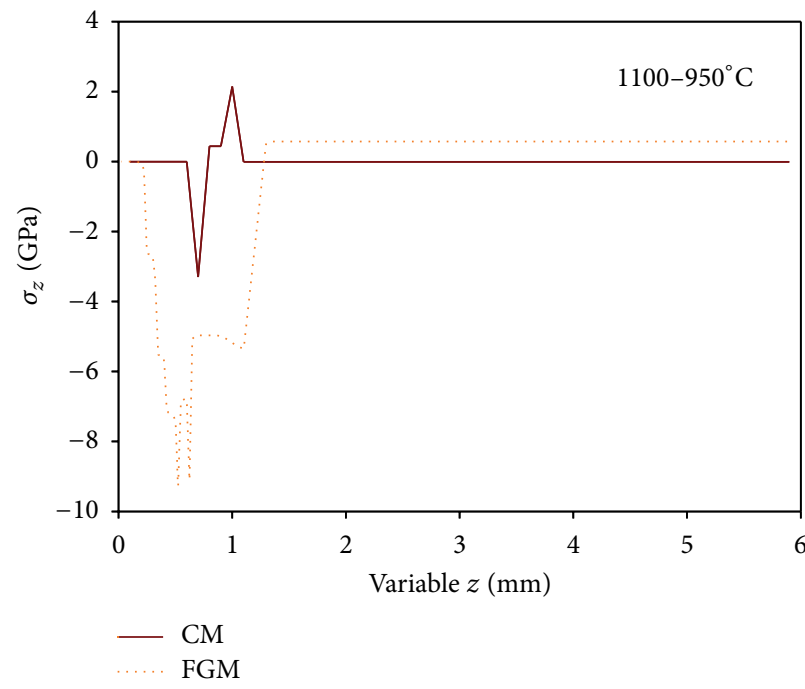

(a)

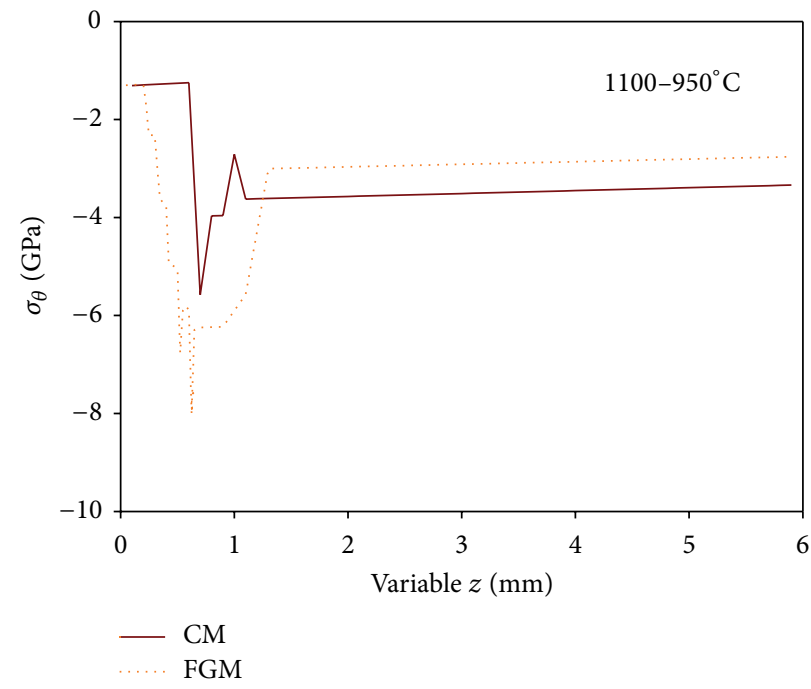

(b)

Figure 6: Stresses in TBCs under the symmetric temperature distribution of $1100-950^{\circ} \mathrm{C}$ : (a) longitudinal stress and (b) circumferential stress.

\section{Conclusion}

The thermoelastic behavior of the FGM (circular disk TBC with FG layer) was investigated and compared with that of the $\mathrm{CM}$ (circular disk TBC without FG layer). The FGM is subject to a lower temperature loading over the entire domain, which reduces the magnitude of the longitudinal displacement. The FG layer in the FGM converts the tensile longitudinal stress appearing at the interface between the bond coat and the substrate of the CM into a compressive stress and increases the magnitude of the compressive stress at the top coat, the FG layer, and the bond coat. Moreover, an insignificant radial stress is developed at the bond coat in the FGM, contributing to the improved performance of the FG layer. Consequently, the thermoelastic characteristics obtained for temperature, displacements, and stresses demonstrate that the FG layer will decrease the risk of failure in the TBC system and the thermal durability of the TBC system can be improved during the lifetime cycle. 


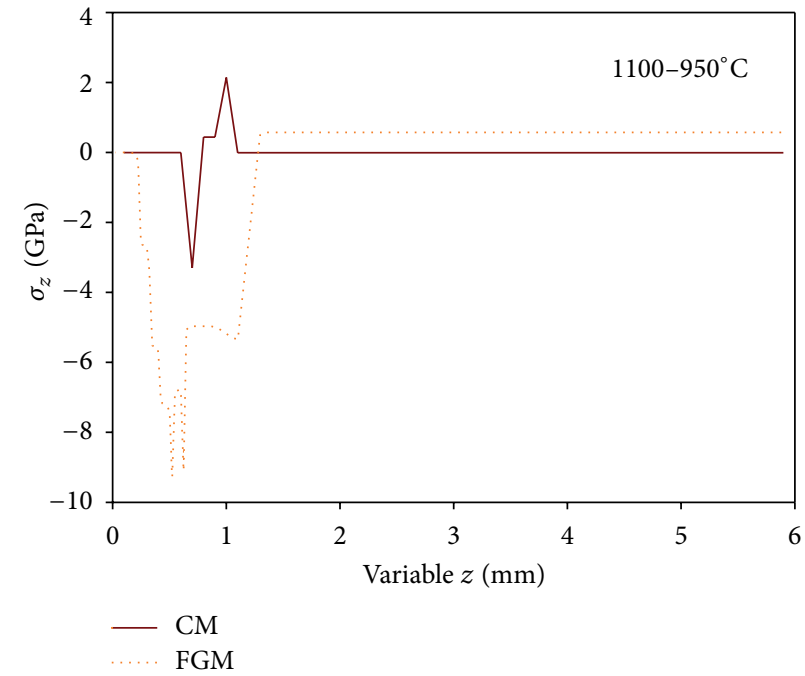

(a)

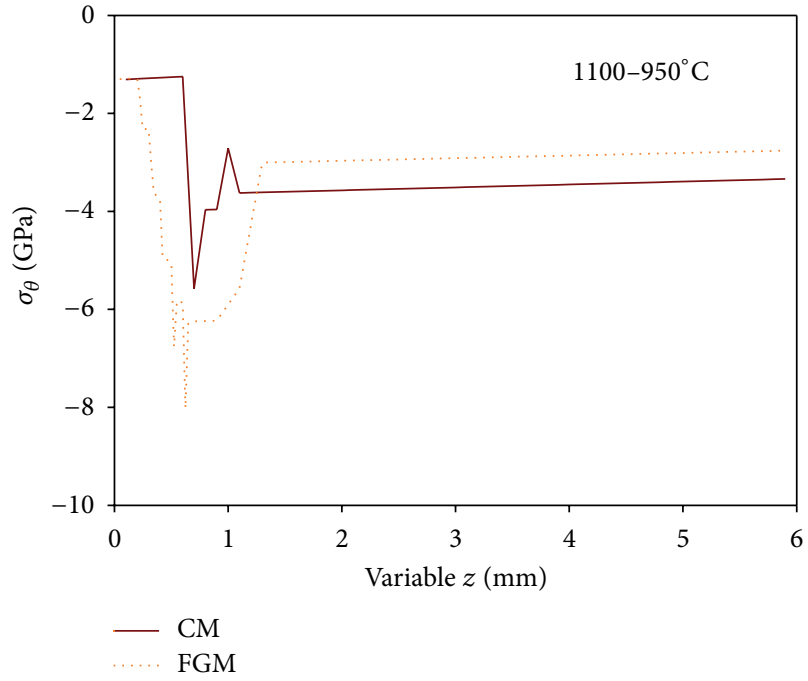

(b)

Figure 7: Radial stresses in TBCs under the symmetric temperature distribution of 1100-950 C: (a) TBC with FG layer and (b) comparison at the bond coat.

\section{Acknowledgments}

This research was supported by the Basic Science Research Program through the National Research Foundation of Korea (NRF) funded by the Ministry of Education, Science and Technology (2010-0024178). This work was supported by a National Research Foundation of Korea (NRF) grant funded by the Korean Government (MEST) (2012-0009450) and by a grant from the Fundamental R\&D Program for Core Technology of Materials funded by the Korean Ministry of Knowledge Economy (10041233).

\section{References}

[1] X. Cao, F. Jin, I. Jeon, and T. J. Lu, "Propagation of Love waves in a functionally graded piezoelectric material (FGPM) layered composite system," International Journal of Solids and Structures, vol. 46, no. 22-23, pp. 4123-4132, 2009.

[2] M. L. Pines and H. A. Bruck, "Pressureless sintering of particlereinforced metal-ceramic composites for functionally graded materials: part I. Porosity reduction models," Acta Materialia, vol. 54, no. 6, pp. 1457-1465, 2006.

[3] E. Ercenk, U. Sen, and S. Yilmaz, "Structural characterization of plasma sprayed basalt-SiC glass-ceramic coatings," Ceramics International, vol. 37, no. 3, pp. 883-889, 2011.

[4] S. Das, A. K. Mukhopadhyay, S. Datta, G. C. Das, and D. Basu, "Hard glass-ceramic coating by microwave processing," Journal of the European Ceramic Society, vol. 28, no. 4, pp. 729-738, 2008.

[5] L. Zhao, W. Q. Chen, and C. F. Lü, "Symplectic elasticity for bidirectional functionally graded materials," Mechanics of Materials, vol. 54, pp. 32-42, 2012.

[6] A. J. Goupee and S. S. Vel, "Transient multiscale thermoelastic analysis of functionally graded materials," Composite Structures, vol. 92, no. 6, pp. 1372-1390, 2010.
[7] G. J. Nie, Z. Zhong, and S. Chen, "Analytical solution for a functionally graded beam with arbitrary graded material properties," Composites B, vol. 44, no. 1, pp. 274-282, 2013.

[8] R. F. Gibson, "Modal vibration response measurements for characterization of composite materials and structures," Composites Science and Technology, vol. 60, no. 15, pp. 2769-2780, 2000.

[9] K. Y. Maalawi, "Use of material grading for enhanced buckling design of thin-walled composite rings/long cylinders under external pressure," Composite Structures, vol. 93, no. 2, pp. 351359, 2011.

[10] I. M. Daniel and O. Ishai, Engineering Mechanics of Composite Materials, Oxford University Press, New York, NY, USA, 2nd edition, 2006.

[11] X.-H. Zhao and W. F. Chen, "The effective elastic moduli of concrete and composite materials," Composites B, vol. 29, no. 1, pp. 31-40, 1998.

[12] K. B. Shin and S. H. Hahn, "Evaluation of the structural integrity of hybrid railway carriage structures including the ageing effects of composite materials," Composite Structures, vol. 68, no. 2, pp. 129-137, 2005.

[13] Y. Li, H. Zhang, N. Zhang, and Y. Dai, "Stress analysis of functionally gradient beam using effective principal axes," International Journal of Mechanics and Materials in Design, vol. 2, no. 3-4, pp. 157-164, 2005.

[14] Z. Zhong and T. Yu, "Analytical solution of a cantilever functionally graded beam," Composites Science and Technology, vol. 67, no. 3-4, pp. 481-488, 2007.

[15] X. L. Chen and K. M. Liew, "Buckling of rectangular functionally graded material plates subjected to nonlinearly distributed in-plane edge loads," Smart Materials and Structures, vol. 13, no. 6, pp. 1430-1437, 2004.

[16] E. Feldman and J. Aboudi, "Buckling analysis of functionally graded plates subjected to uniaxial loading," Composite Structures, vol. 38, no. 1-4, pp. 29-36, 1997.

[17] K. D. Kim, Gilson Rescober Lomboy, and S. C. Han, "Geometrically non-linear analysis of Functionally Graded Material (FGM) plates and shells using a four-node quasi-conforming 
shell element," Journal of Composite Materials, vol. 42, no. 5, pp. 485-511, 2008.

[18] Y. Obata and N. Noda, "Steady thermal stresses in a hollow circular cylinder and a hollow sphere of a functionally gradient material," Journal of Thermal Stresses, vol. 17, no. 3, pp. 471-487, 1994.

[19] K. M. Liew, S. Kitipornchai, X. Z. Zhang, and C. W. Lim, "Analysis of the thermal stress behaviour of functionally graded hollow circular cylinders," International Journal of Solids and Structures, vol. 40, no. 10, pp. 2355-2380, 2003.

[20] X. Wang, R. T. Wu, and A. Atkinson, "Characterisation of residual stress and interface degradation in TBCs by photo-luminescence piezo-spectroscopy," Surface and Coatings Technology, vol. 204, no. 15, pp. 2472-2482, 2010.

[21] A. C. Karaoglanli, E. Altuncu, I. Ozdemir, A. Turk, and F. Ustel, "Structure and durability evaluation of $\mathrm{YSZ}+\mathrm{Al}_{2} \mathrm{O}_{3}$ composite TBCs with APS and HVOF bond coats under thermal cycling conditions," Surface and Coatings Technology, vol. 205, no. 2, pp. S369-S373, 2011.

[22] Y. H. Sohn, E. Y. Lee, B. A. Nagaraj, R. R. Biederman, and R. D. Sisson Jr., "Microstructural characterization of thermal barrier coatings on high pressure turbine blades," Surface and Coatings Technology, vol. 146-147, pp. 132-139, 2001.

[23] C. Batista, A. Portinha, R. M. Ribeiro, V. Teixeira, M. F. Costa, and C. R. Oliveira, "Morphological and microstructural characterization of laser-glazed plasma-sprayed thermal barrier coatings," Surface and Coatings Technology, vol. 200, no. 9, pp. 29292937, 2006.

[24] F. Cernuschi, P. Bison, and A. Moscatelli, "Microstructural characterization of porous thermal barrier coatings by laser flash technique," Acta Materialia, vol. 57, no. 12, pp. 3460-3471, 2009.

[25] S.-I. Jung, J. H. Kim, J. H. Lee, Y. G. Jung, U. Paik, and K. S. Lee, "Microstructure and mechanical properties of zirconia-based thermal barrier coatings with starting powder morphology," Surface and Coatings Technology, vol. 204, no. 6-7, pp. 802-806, 2009.

[26] A. Kulkarni, A. Goland, H. Herman et al., "Advanced neutron and X-ray techniques for insights into the microstructure of EB-PVD thermal barrier coatings," Materials Science and Engineering A, vol. 426, no. 1-2, pp. 43-52, 2006.

[27] U. Schulz and M. Schmücker, "Microstructure of $\mathrm{ZrO}_{2}$ thermal barrier coatings applied by EB-PVD," Materials Science and Engineering A, vol. 276, no. 1-2, pp. 1-8, 2000.

[28] X. Chen, L. Gu, B. Zou, Y. Wang, and X. Cao, "New functioanlly graded thermal barrier coating system based on LaMgAl11O19/ YSZ prepared by air plasma spraying," Surface and Coatings Technology, vol. 206, no. 8-9, pp. 2265-2274, 2012.

[29] U. Schulz, M. Peters, F. W. Bach, and G. Tegeder, "Graded coatings for thermal, wear and corrosion barriers," Materials Science and Engineering A, vol. 362, no. 1-2, pp. 61-80, 2003.

[30] L. L. Shaw, "Thermal residual stresses in plates and coatings composed of multi-layered and functionally graded materials," Composites B, vol. 29, no. 3, pp. 199-210, 1998. 


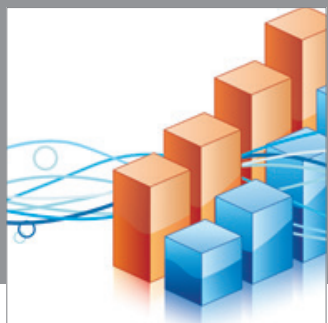

Advances in

Operations Research

mansans

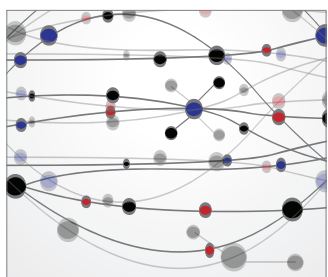

The Scientific World Journal
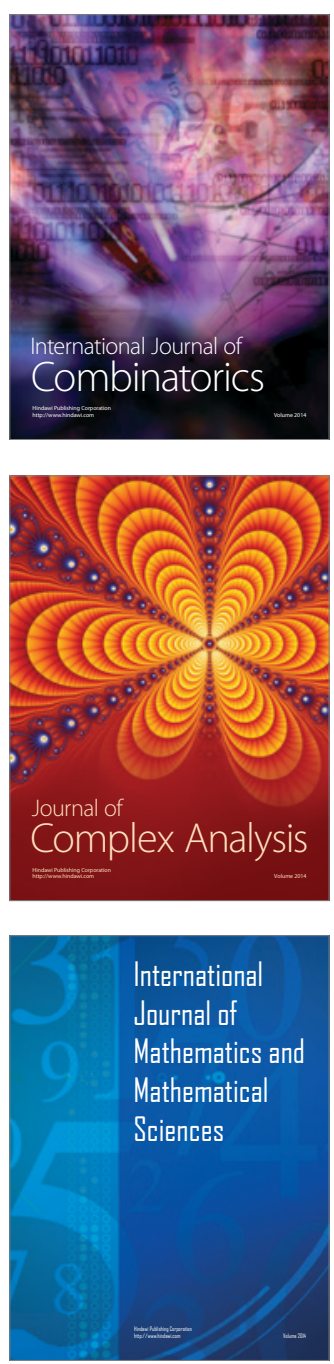
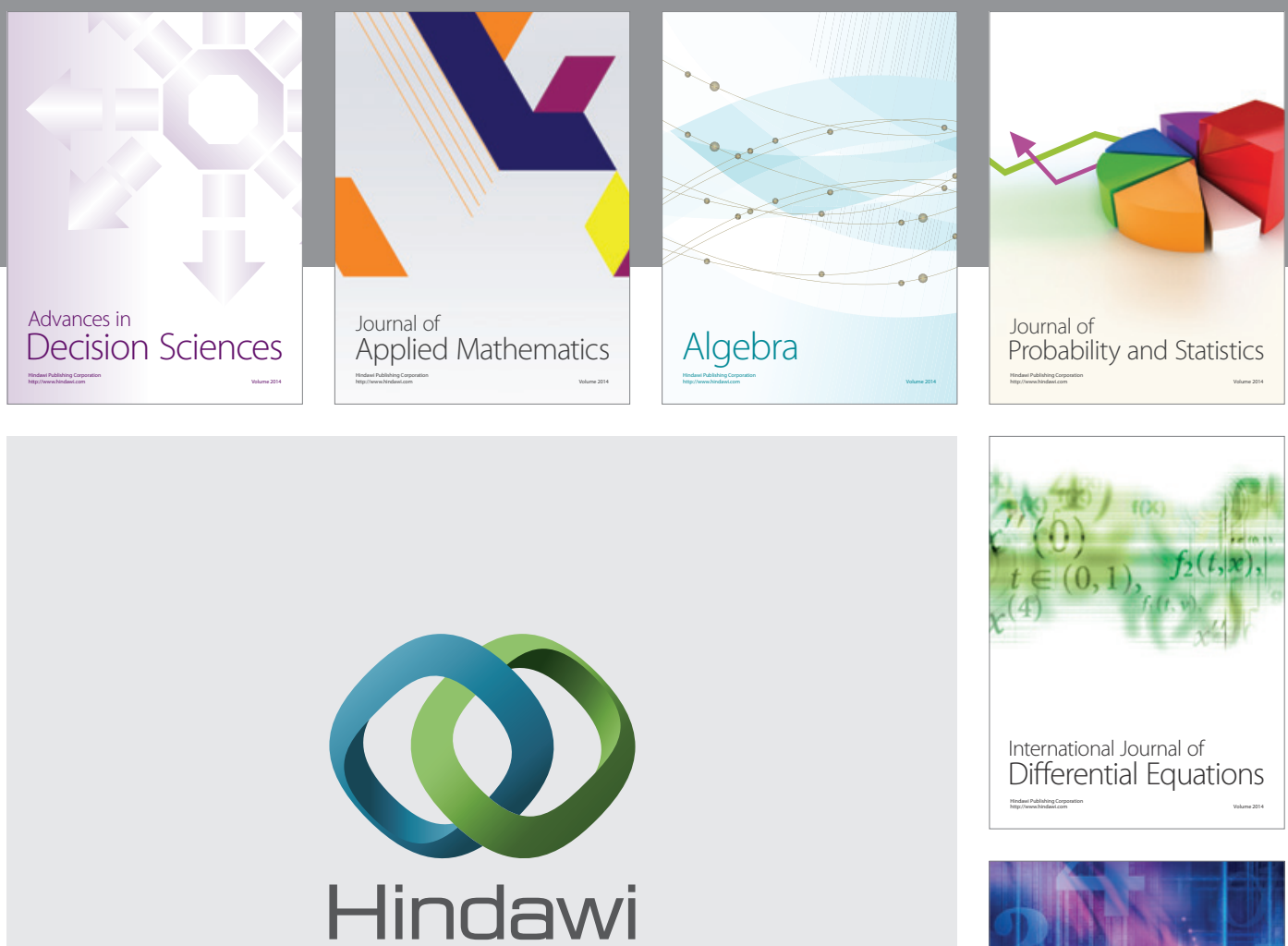

Submit your manuscripts at http://www.hindawi.com
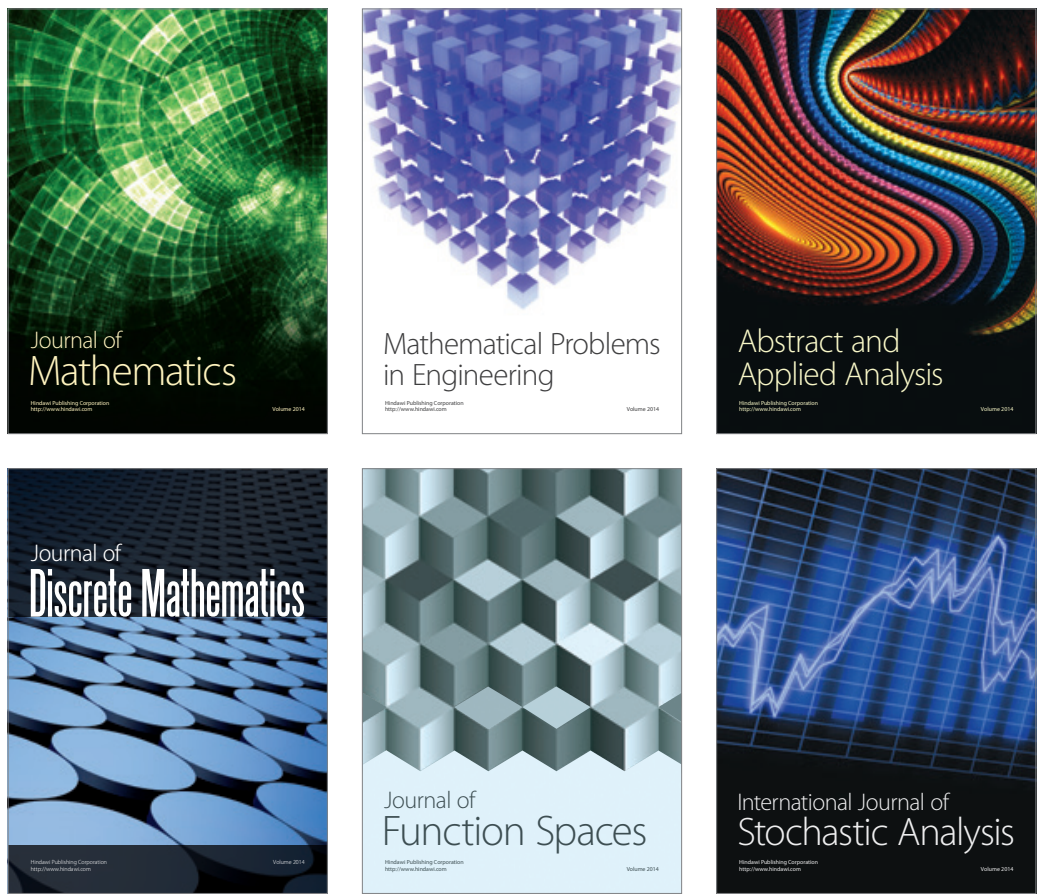

Journal of

Function Spaces

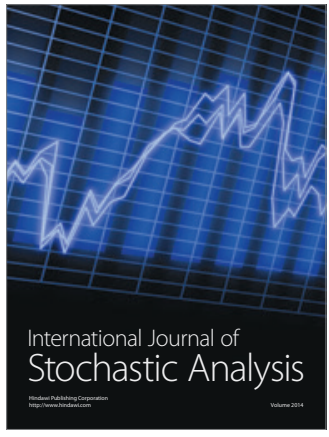

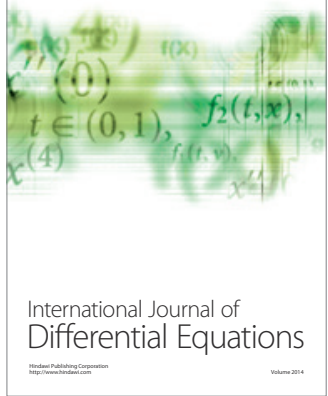
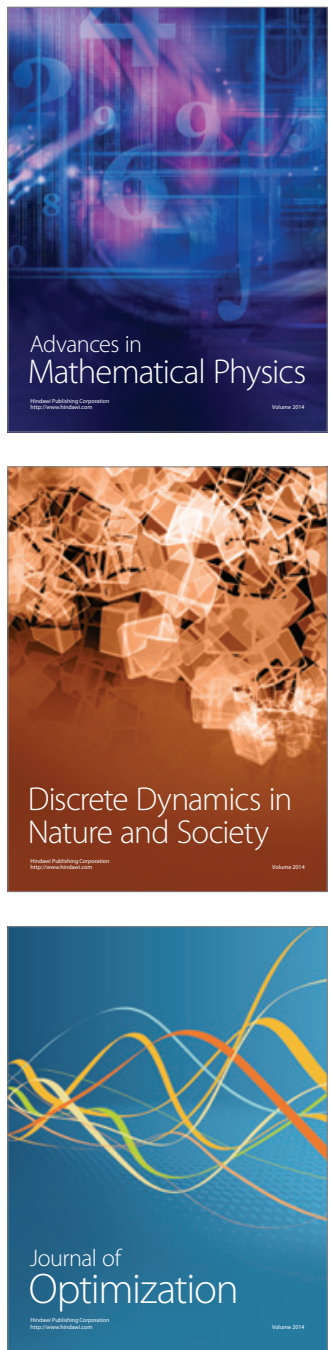